\title{
Geospatial Monitoring and Structural Mechanics Models: a Case Study of Sports Structures
}

\author{
Roman Shults (D) 1*, Saule Soltabayeva², Gulnur Seitkazina ${ }^{3}$, \\ Zhupargul Nukarbekova ${ }^{4}$, Oksana Kucherenko ${ }^{5}$ \\ ${ }^{1,5}$ Department of Engineering Geodesy, School of GIS and Land Management, \\ Kyiv National University of Construction and Architecture, Kyiv, Ukraine \\ ${ }^{2,3,4}$ Department of Mining and Geodesy, K. Turysov Institute of Geology, Oil and Mining, \\ Satpayev University, Almaty, Kazakhstan
}

Received 22 February 2020; accepted 03 March 2020

\begin{abstract}
The task of geospatial monitoring is one of the most common in the practice of geodetic works. In the twentieth century, the basic principles for carrying out geospatial monitoring, accuracy calculation, observation intervals assignment, and data simulation were developed. However, since that time, both the building and geodetic technologies have been changed considerably. Among modern engineering structures, the building technology of which has undergone significant changes are sport structures. The use of the state-of-the-art sport structures is associated with the presence of specific loads, name a few: the impact of a vast number of spectators (e.g., stadiums, cycle tracks, etc.) or loads directly from the competitions equipment (e.g., bobsleigh tracks, race tracks, etc.). The primary goal of the presented paper is to develop a general approach to the preliminary accuracy calculation of the geospatial monitoring of the sports structures using the methods of structural mechanics. As an example, a football stadium was considered. Based on the simulation, the improved technology of geospatial monitoring for the sports structure was suggested. The in-depth analysis of the creation of geodetic networks for geospatial monitoring was accomplished. At the final step, the results of geospatial monitoring for the football stadium were analyzed, and hands-on recommendations were made.
\end{abstract}

Keywords: structural mechanics, geodetic monitoring, displacements, accuracy, stadiums, geodetic network.

\section{Introduction}

The task of geodetic monitoring is one of the most common in geodesy. To date, the developed models for the accuracy determination are based on accepted conventional models, which describe the deformation of engineering structures very approximately. The main shortcoming is the treating of the engineering structure as a static object, in which movements occur according to the same laws, and different parts of the building are considered as homogeneous. This approach is leading to an improper accuracy assignment. The mounting of the deformation marks based on the experience of the observer and has no scientific basis. The recommended methods and models for the accuracy assignment, methods, and technologies for monitoring, and mathematical models for processing monitoring results were based on a completely distinct situation in the construction industry. First of all, we note two important factors: the geometric parameters of the structures being built have significantly changed (length, height, diameter, etc.); the conditions for the construction of structures have evolved (there are no restrictions related to environmental conditions or the type of foundation under the structure, the possibilities of erecting structures in seismic zones have been significantly expanded). From this point of view, it is evident that modern structures (buildings, tunnels, shells, etc.) experience more complex loads, which, in turn, leads to more complex deformation processes. Sports facilities are certainly belonging to the modern engineering structures, the construction technology of which has undergone significant changes. The employment of sports structures is associated with the presence of specific loads, such as the impact of a vast number of spectators (stadiums, cycle tracks) or loads directly from the competition equipment (bobsleigh tracks, race tracks). A comprehensive model of the structure-ground-environment interaction is widely used for the calculation of the expected displacements of structures. The calculations are performed by the methods of structural mechanics, either using differential equations or the finite element method (Connor \& Faraji, 2016).

The literature shows no consensus on the problem of the accuracy assignment, which means that this problem is essential. Despite the high importance of the question, previous researches have largely overlooked the problem of accuracy. A number of scholars have stressed the importance of the accuracy assignment (Welsch \& Heunecke, 2001;

\footnotetext{
${ }^{*}$ Corresponding author. E-mail: shultsrv@gmail.com
}

\section{Copyright (C) 2020 The Author(s). Published by VGTU Press}

This is an Open Access article distributed under the terms of the Creative Commons Attribution License (http://creativecommons.org/licenses/by/4.0/), which permits unrestricted use, distribution, and reproduction in any medium, provided the original author and source are credited. 
Szostak-Chrzanowski et al., 2001; Szostak-Chrzanowski \& Chrzanowski, 2004; Jäger \& González, 2005; Eichhorn, 2007). However, relatively little had been done on that and researches are not without controversy (Cîrdei \& Onose, 2019; Acosta et al., 2018; Alizadeh-Khameneh et al., 2018; Gikas \& Sakellariou, 2008; Li et al., 2007; Hesse et al., 2006; Kapović et al., 2005). In this study, we put forward the claim that there is only one correct and modern approach to assigning the accuracy of geodetic monitoring. It is based on using the maximum allowable displacement for engineering structures. To determine the accuracy of geodetic monitoring, as a function of displacements, it is enough to use simplified models of structural mechanics. This approach is considered in the presented study. The work aims to develop a general approach to the preliminary accuracy calculation of the geodetic monitoring of sports structures using methods of structural mechanics.

The initial stuff for the writing of this work is the scientific research performed during the development and deploying of the geodetic works project for the reconstruction of the biggest football stadium in Ukraine, NSC "Olimpiysky". The geospatial monitoring data were gathered during construction works before the stadium employment.

\section{Object of research}

During the preparation of Ukraine for the European Football Championship EURO 2012, substantial work was done in the country to build the new and reconstruct existing football stadiums. So for the time from 2007 to 2011 , the stadiums "Donbass Arena" (Donetsk), "Arena Lviv" (Lviv), "Dnepr Arena" (Dnipro) were built, and the NSC "Olimpiysky" (Kyiv), USC "Metalist" (Kharkiv), "Chernomorets" (Odesa) were reconstructed. After the competitive selection of UEFA, four of the stadiums listed were given the right to host matches of the European Championship. It should be noted that all of the listed football arenas meet the UEFA criteria, and according to UEFA requirements, they are assigned the highest 4th category. The reconstruction of NSC “Olimpiysky" had begun in June 2008. The reconstruction supposed three steps: dismounting of the lower tier and its reconstruction; renovation of the upper tier; roof assembling. The renovated NSC "Olimpiysky" is a complex structure, the main elements of which are precast metal columns about $40 \mathrm{~m}$ high, interconnected by metal beams $11 \mathrm{~m}$ long, fixed in the middle and upper parts of the column. The layout of the stadium roof project is shown in Figure 1.

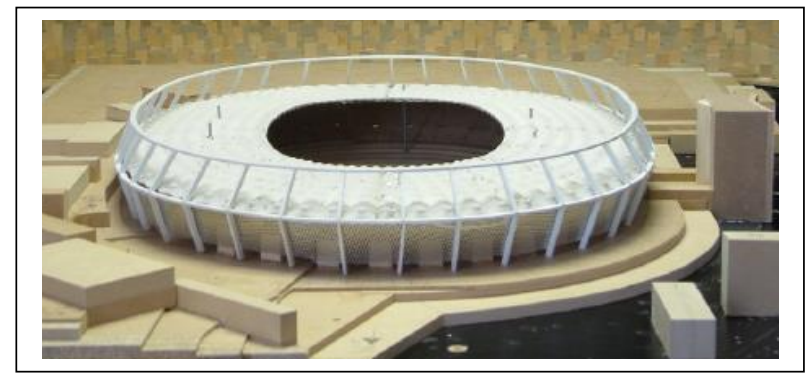

Figure 1. The view of the layout of renovated NSC "Olimpiysky"

The roof columns are located outside the upper tier of the stadium. From each column pulled two cables, upper and lower, to which attached the compressed inner ring. It is obvious that the most responsible steps were the dismounting of the lower and the upper tier. During these steps, the existing lower and upper tiers were disconnected, which could lead to displacements of existing constructions (Figure 2).

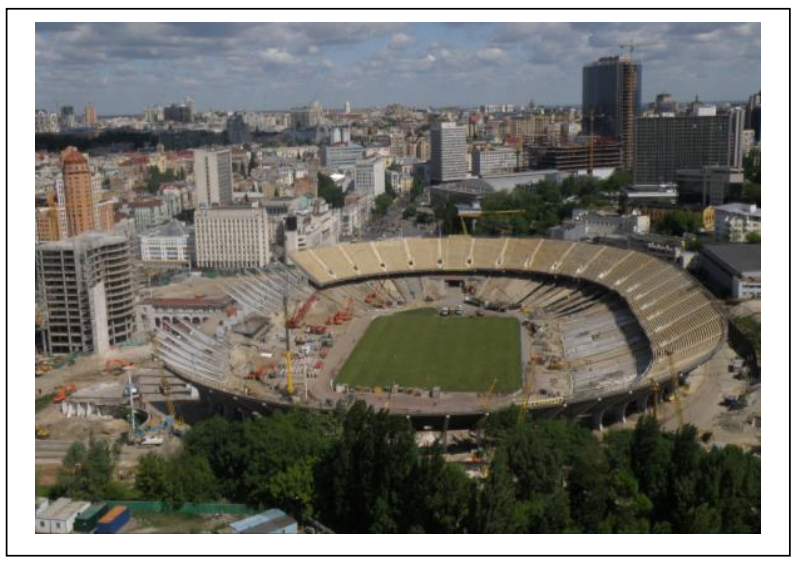

Figure 2. The picture of the reconstruction with partially disconnected tiers 
The stadium's geodetic service had organized the system of geospatial monitoring to find and control the displacements of the lower and the upper tier. However, it remained unanswered questions concerning the accuracy of the monitoring. To overcome this drawback, one had suggested using the theory of the stress-strain state as a core element of the structural mechanic's methods. Under this premise, the association between stress-strain state, allowable displacements, and monitoring accuracy was investigated.

\section{Structural mechanics models for accuracy assignment}

It is necessary to know the quantity of the allowable displacement $\Delta S$ of the engineering structure to establish the accuracy of observations. The allowable displacement is considered in three dimensions with the corresponding components $\Delta S_{x}, \Delta S_{y}, \Delta S_{z}$. In fact, the allowable displacements are the sum of three displacements: the actual displacement of the structure under its weight $\Delta l_{x}, \Delta l_{y}, \Delta l_{z}$; temperature loads and other external influences $\Delta t_{x}, \Delta t_{y}$, $\Delta t_{z}$; the ground displacements of the structure as a function of the pressure of the weight of the structure $w$ on the base $\Delta g_{x}(w), \Delta g_{y}(w), \Delta g_{z}(w)$. So we have the following dependencies:

$$
\begin{aligned}
& \Delta S_{x}=\Delta l_{x}+\Delta t_{x}+\Delta g_{x}(w) ; \\
& \Delta S_{y}=\Delta l_{y}+\Delta t_{y}+\Delta g_{y}(w) \\
& \Delta S_{z}=\Delta l_{z}+\Delta t_{z}+\Delta g_{z}(w) \\
& \Delta S=\sqrt{\Delta S_{x}^{2}+\Delta S_{y}^{2}+\Delta S_{z}^{2}} .
\end{aligned}
$$

In structural mechanics for simple structures (frames, trusses, etc.) there is a well-known relationship:

$$
e=e_{\text {force }}+e_{\text {temperature }}+e_{\text {manufactoring }} \text {. }
$$

The expression (2) describes the member extension as a sum of partial extensions due to loads (dead load), temperature, and member's manufacturing error. The relationship between extensions and displacements is being presented in matrix expression:

$$
\mathbf{e}=\mathbf{B}^{\prime T} \mathbf{U}^{\prime}
$$

In this expression, the support's movements are also included. We may treat the supports movements as the ground displacements. If the structure is statically determinate, one may estimate the supports' movements from the Eq. (3). Then it is possible to find appropriate displacements through the equations:

$$
\begin{gathered}
\mathbf{F}=\mathbf{B}^{-1} \mathbf{P} \\
\mathbf{e}=\mathbf{f F}+\mathbf{e}_{1} \\
\mathbf{U}=\left(\mathbf{B}^{-1}\right)^{T} \mathbf{e} .
\end{gathered}
$$

The designator $\mathbf{U}$ is typical for displacements vector in structural mechanics. In what follows, we replaced it with $\Delta \mathbf{S}=\mathbf{U}$. The model of displacements computation (4) is quite complicated. Here it worth to mention that this model works only for statically determinate structures. In other cases, we have a structure with a number of degrees of freedom, which in turn means the necessity of using the stiffness approach. The structure of NSC "Olimpiysky" was considered as spatial truss structure. The interaction of the structure with the ground occurs through the foundation of the structure. The deformation of the ground under the structure depends on the shape and geometry of the foundation. Such interaction complicates the model "construction-foundation-ground" and the calculation of the maximum displacement of the structure. Nevertheless, construction science has developed a vast number of calculation models for the shown conditions, which can be successfully used by surveyors. Among such models, a prominent place takes the finite element method. That method has been used for the calculation of the displacements in the presented study.

The simulation results have shown that maximum displacements reach the values $\Delta S_{p}=30 \mathrm{~mm}$ for horizontal deformation and $\Delta S_{z}=40 \mathrm{~mm}$ for vertical deformation, respectively. According to a well-known approach from applied geodesy, one may assign the accuracy of the monitoring $m_{\Delta S_{p}}, m_{\Delta S_{z}}$ using the following rules:

$$
\begin{gathered}
m_{\Delta S_{p}}=0.2 \sqrt{\Delta S_{x}^{2}+\Delta S_{y}^{2}}=6 \mathrm{~mm} \\
m_{\Delta S_{z}}=0.2 \Delta S_{z}=8 \mathrm{~mm}
\end{gathered}
$$

Under this assumption, the allowable errors in geospatial monitoring should not lead to additional forces in structure members that exceed $20 \%$. The accuracy that has been obtained from expressions (5) now could be used for 
choosing the methods and technologies for the monitoring, and mathematical models for processing monitoring results. But, foremost, we have used it for assignment the accuracy of geodetic networks for monitoring.

\section{Design of geodetic network for geospatial monitoring}

The problem of creating a geodetic network for geospatial monitoring is always relevant since it is associated with the unique configuration of the structure and its location relative to surrounding objects. The accuracy of such a network is established based on the requirements for the monitoring accuracy $m_{\Delta S}$. At the same time, we aim to reduce the error of the geodetic network $m_{n e t}$ to a negligible level comparing to the overall error of geospatial monitoring:

$$
\begin{aligned}
& m_{\text {net }_{p}} \leq \frac{1}{3} m_{\Delta S_{p}} \leq 3 \mathrm{~mm}, \\
& m_{\text {net }_{z}} \leq \frac{1}{3} m_{\Delta S_{z}} \leq 3 \mathrm{~mm} .
\end{aligned}
$$

However, it is not always possible to meet the conditions (6). Then the geodetic network is created with the highest possible accuracy, and the balance of accuracy is achieved by increasing the accuracy of other geodetic works.

The geodetic engineering networks are created step by step with the development from more accurate networks to less accurate ones. This approach is most successful when creating a geodetic network for an object under construction. During the reconstruction of existing objects, as in our case, the situation is much more complicated, as the stages of development of the geodetic network are linked to the construction works.

Because the object is in an urban area, the creation of a geodetic network has some pre-requirements:

- to the location of network points;

- to the stability of the position of network points both during the construction and exploitation;

- to compliance with the requirements for the accuracy of monitoring;

- to the accuracy of geodetic equipment.

Designing such a network is extremely difficult due to:

- lack of places for setting points up to a depth of stable soils;

- difficult conditions of the construction site due to excavation and construction works are performed;

- complexity of providing visibility between points of the geodetic network;

- possible deformation of existing and built structures;

- points of the network should be located as close as possible to the structure to ensure the necessary accuracy.

Given the high requirements for accuracy, it was decided that the most rational for horizontal displacements is a special linear-angular geodetic network. According to the law of measurement error distribution, the errors of the previous levels of the geodetic network influence the errors of the following levels. The following expression for the four-level network has been suggested:

$$
m_{\text {net } p}^{2}=k_{1}^{2} m_{1}^{2}+k_{2}^{2} m_{2}^{2}+k_{3}^{2} m_{3}^{2}+k_{4}^{2} m_{4}^{2} .
$$

In the expression (7) the coefficients of accuracy relationship have been assigned sequentially, namely, $k_{1}=0.5$, $k_{2}=1.0, k_{3}=1.5, k_{4}=2.0$. For such conditions, the network has four levels. The errors of partial geodetic networks were being considered equal $m_{1}=m_{2}=m_{3}=m_{4}=m_{i}$. The balance of the accuracy for linear $m_{L}$ and angular $m_{\beta}$ measurements has been determined as follows:

$$
m_{i}=\sqrt{m_{L}^{2}+m_{\beta}^{2} L^{2} / \rho^{2}} ; m_{L}=m_{\beta} L / \rho=\frac{m_{i}}{\sqrt{2}} .
$$

Calculations of the accuracy of geodetic measurements in networks for an average distance to monitoring points ( $L=80 \mathrm{~m}$ ) are given in Table 1 .

An internal network (level I) of seven points C, F1, F2, B1, B2, B3, B4 was designed directly on the stadium field to perform the monitoring of the lower tier elements of NSC "Olimpiysky". Points C, F1, F2 are fixed with concrete monoliths to a depth of 70-80 cm, points B1, B2, B3, B4 are the fundamental benchmarks mounted to a depth of $8 \mathrm{~m}$ to solid rocks with the arrangement of external signs for the installation of total station and reflectors. The presence of fundamental benchmarks B1-B4 allowed developing a geodetic network. An external geodetic network (level II) was designed to carry out the monitoring of the upper tier elements. The third-level network was created to densify the previous two. The last, the fourth-level network, is a network of free stations for the direct observations of inaccessible points (Figure 3). 
Table 1. The accuracy of measurements for four-level and three-level networks

\begin{tabular}{|c|c|c|c|}
\hline Levels (4/3) & Linear measurements (4/3), mm & Angular measurements (4/3), sec & Network accuracy (4/3), mm \\
\hline (I) & $1.1 / 0.8$ & $2.8 / 2.1$ & $1.6 / 1.1$ \\
\hline (II) & $2.3 / 1.6$ & $5.8 / 4.1$ & $3.2 / 2.2$ \\
\hline (III) & $3.4 / 2.3$ & $8.8 / 5.9$ & $4.8 / 3.3$ \\
\hline (IV) & 3.1 & 8.0 & 4.4 \\
\hline
\end{tabular}

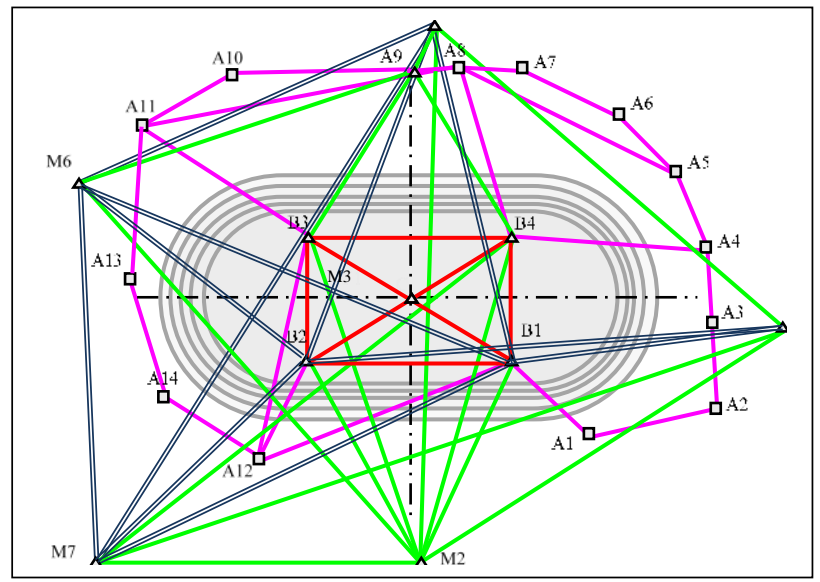

Figure 3. The scheme of the multilevel geodetic network for geospatial monitoring of horizontal displacements

The leveling network (Figure 4) for geospatial monitoring has been designed according to the same premises as a horizontal network.

$$
m_{n e t h}=k_{1}^{2} m_{h 1}^{2}+k_{2}^{2} m_{h 2}^{2}+k_{3}^{2} m_{h 3}^{2} .
$$

In the expression (9) the coefficients of accuracy relationship have been assigned sequentially, namely, $k_{1}=0.5$, $k_{2}=1.0, k_{3}=1.5$. For such conditions, the network has three levels. The errors of partial leveling networks were being considered equal $m_{1}=m_{2}=m_{3}=m_{i}$. Given the necessary accuracy for vertical displacements $m_{\Delta S_{z}}=8 \mathrm{~mm}$, it was defined the accuracy for different levels $m_{h 1}=2.1 \mathrm{~mm}, m_{h 2}=4.3 \mathrm{~mm}, m_{h 3}=6.4 \mathrm{~mm}$.

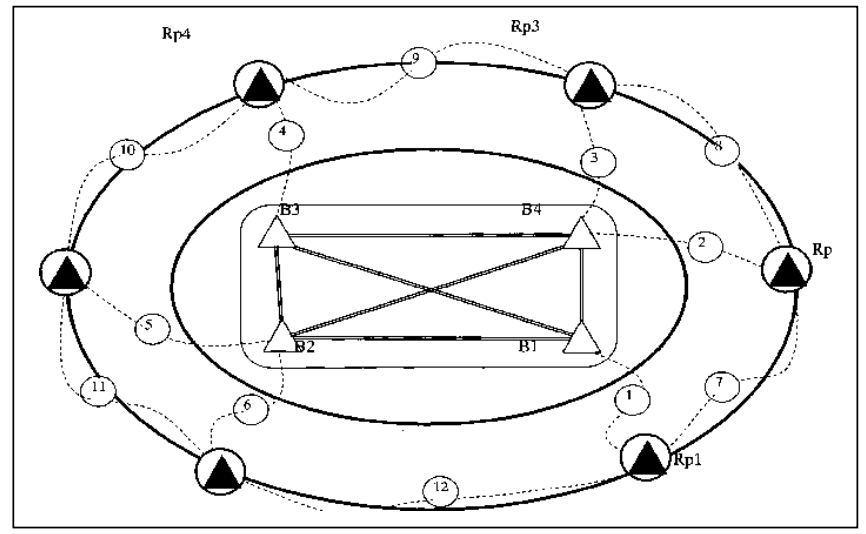

Figure 4. The scheme of multilevel leveling network

The points of the internal leveling network are located up to a distance of $80 \mathrm{~m}$. The heights between them were determined by spirit leveling. All the rest measurements were being made by trigonometric leveling.

\section{Results analysis}

Eighty concrete columns supported the stadium's upper tier. Seventeen columns were dismounted, and the ground under them was excavated. As a consequence, the lower and upper tier became disconnected, which in turn led to the 
horizontal and vertical displacements of the rest of the columns (12-71). Each column was marked with two small reflectors to control the change of the displacements. One reflector was placed at the bottom of the column and another at the top. In what follows, the spatial coordinates of these reflectors were used for the control of the column roll and bending. From the points of linear-angular and leveling networks, the displacements of the reflectors were being determined. The horizontal displacements were being measured by the method of the free station. The vertical displacements were being measured by the method of trigonometric leveling. Below are presented and analyzed the results of geospatial monitoring for vertical displacements. These results have been chosen for the presentation insofar as they have some remarkable features. The geospatial monitoring spans the period from June 2008 to December 2009. Due to construction works, namely, the disassembling of some parts of the existing structure, the monitoring was interrupted from October 2008 till December 2008. Before we analyze the data, it would be wise to present an array of displacements during the whole observation time (Figure 5).

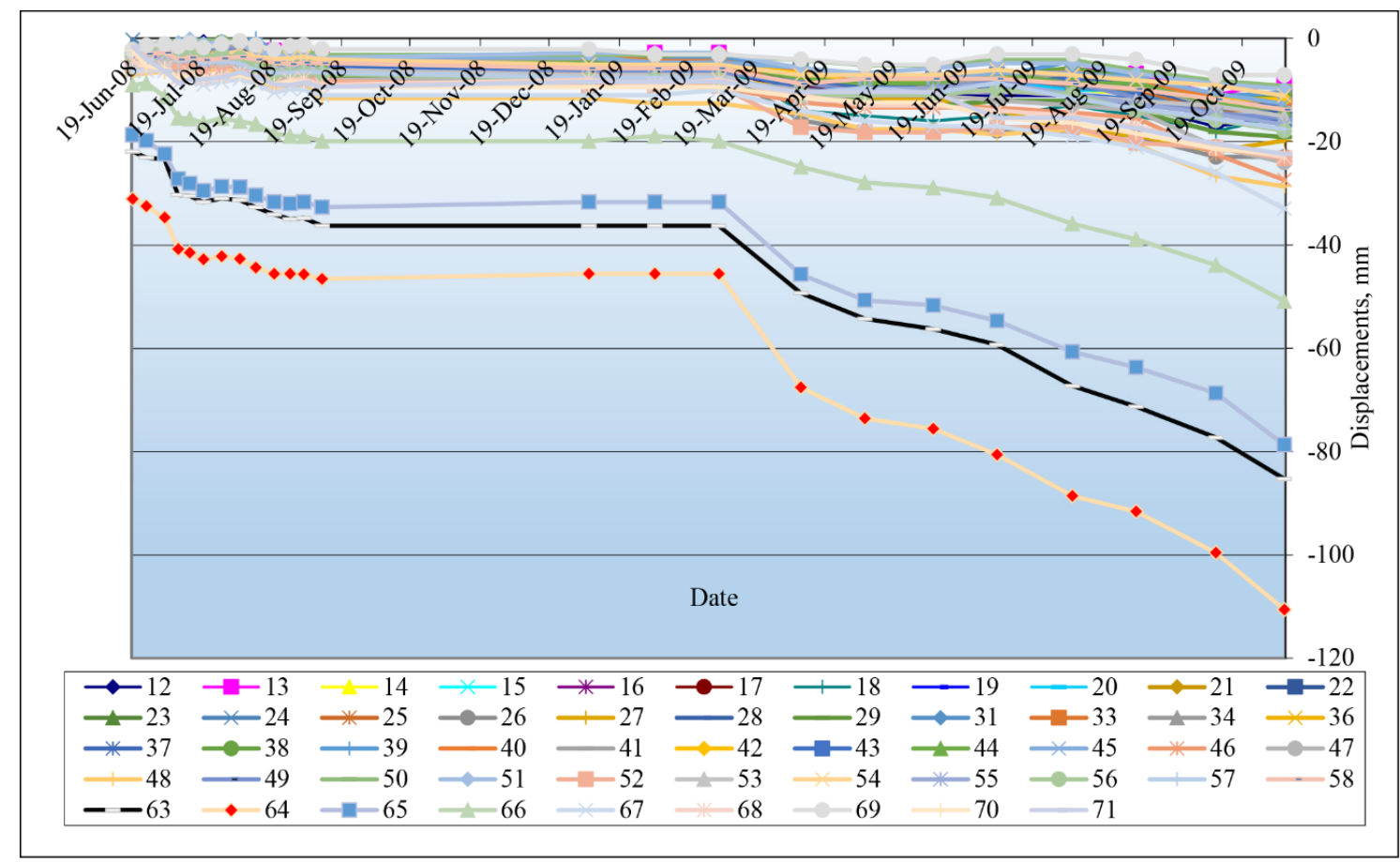

Figure 5. The picture of displacements' growth

In Figure 5, the numbers in the legend at the bottom designate columns' numbers. The data gathered in the study suggest that it makes sense to analyze them separately. In the first step, it is wise to consider the measurements that lasted from June 2008 to October 2008 (Figure 6).

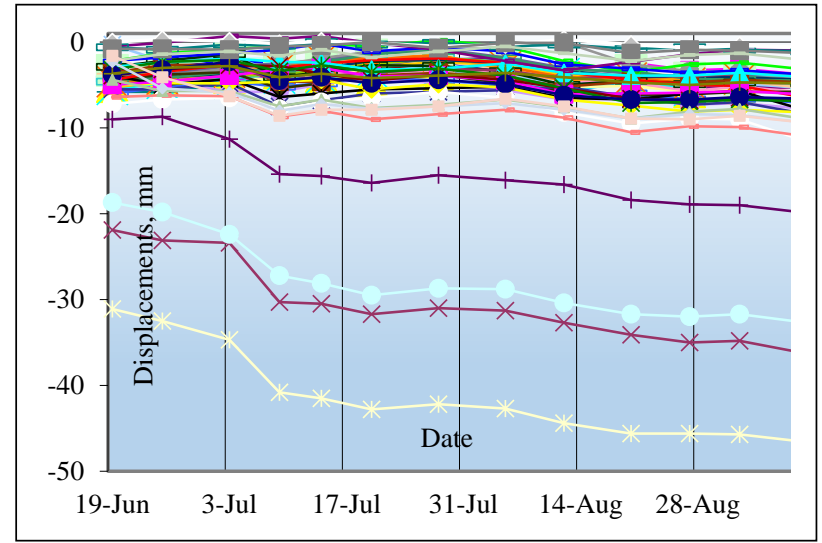

Figure 6. The picture of displacements' progress from June 2008 to October 2008

The key feature of these measurements is that most of them had been carried out in the summertime. It means that it is mandatory to consider the results tailored to the temperature effect. That is clear that the heights of the reflectors were changing due to cool down the constructions in a fall. Using the expressions similar to (2)-(4), we had 
calculated the temperature correction and inputted it into received displacements. The average value of the temperature correction equals $-2 \mathrm{~mm}$. The displacements free of temperature effect is presented in Figure 7. The main conclusion that might be drawn from these data consist of that all displacements are in allowable accuracy range $\pm 6 \mathrm{~mm}$. That, in turn, means that there are no significant vertical displacements for these columns. One may notify that in Figure 7, that four observations have been excluded from the whole dataset. There are four columns, spaced next to each other that experienced the maximum displacements. These outside values excluded from the dataset and analyzed separately. The average values of vertical displacements per each cycle have been calculated with and without these extreme values (Figure 8).

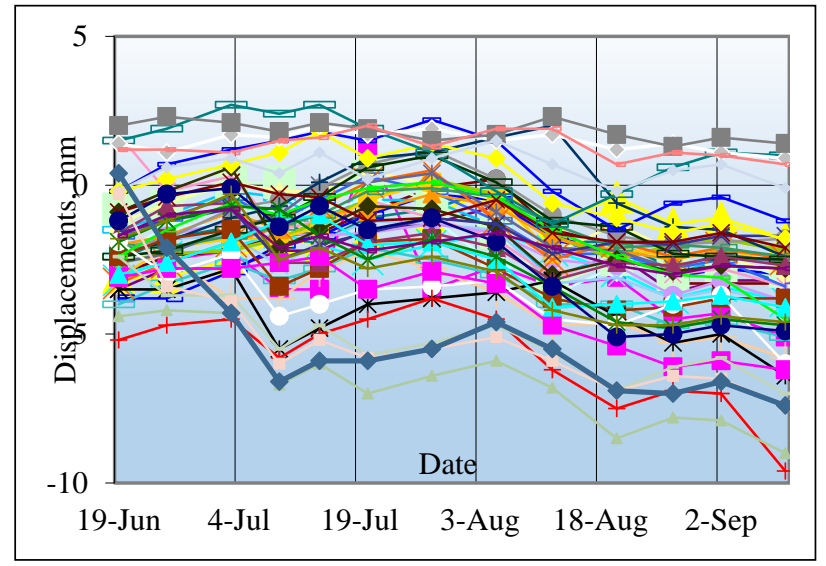

Figure 7. The picture of displacements free of the temperature effect

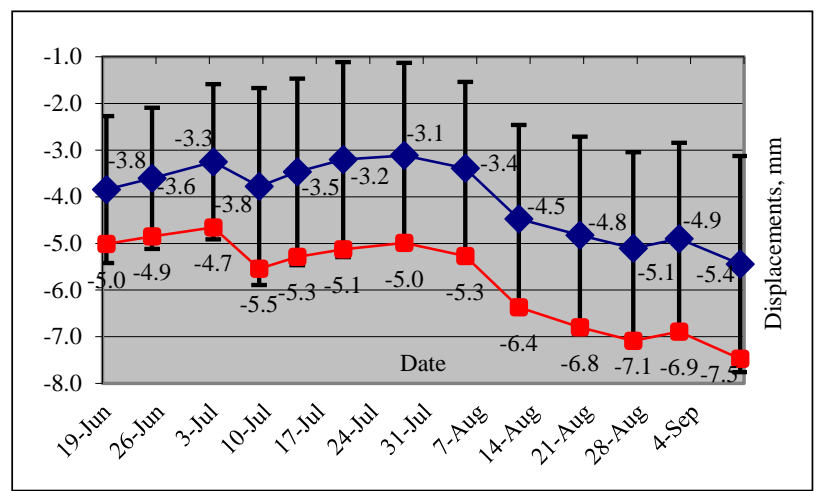

Figure 8. Average values of vertical displacements per observation cycle

The figure reveals that the displacements of those four columns had changed the value of mean structure displacement considerably. The mean values curve of displacements without extreme values (upper graph) has been drawn with confidence intervals of standard deviations for each cycle. The data provide convincing evidence that these columns experienced significant displacements. This statement has been proved by observations from December 2008 until December 2009 (Figure 9).

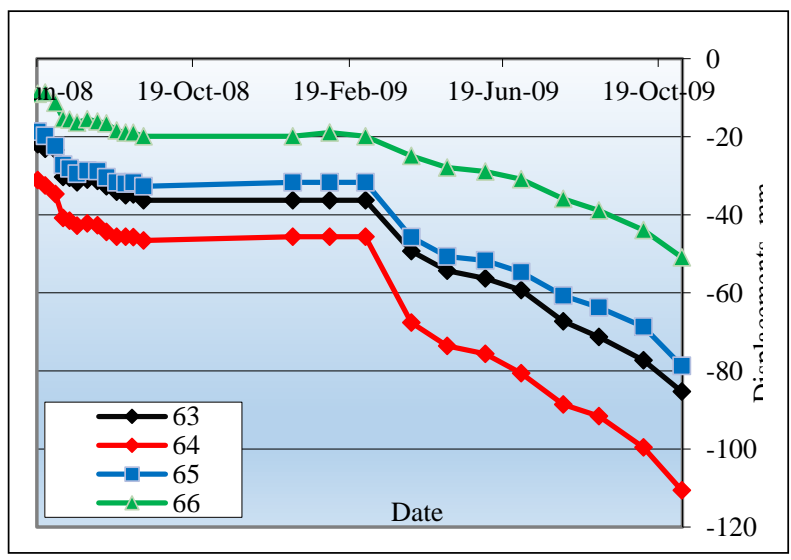

Figure 9. Graphs of vertical displacements for columns 63-66 
Comparing these data with limit displacement given in section two, $\Delta S_{z}=40 \mathrm{~mm}$, one may infer that only these columns (63-66) have reached and exceeded the allowable value. A closer look at the data indicates that the deformation process for these columns is far from stabilization. Moreover, the view of the curves does not fit any conventional models of deformation processes. That is why the contractor had decided to prolong geospatial monitoring. The observations were continued for the next year and were finished after the reconstruction process was accomplished.

\section{Conclusions}

The paper aimed to develop a general approach to the preliminary accuracy calculation of the geospatial monitoring of the sports structures using the methods of structural mechanics. The results yielded by this study provide strong evidence that the offered approach is the strictest among existing methods of accuracy assignment. Two main arguments can be advanced to support the approach based on structural mechanics methods. The first one is that this approach accounts for all possible loads on a structure and consequently gives a real picture of the deformation process with real values of displacements. The second, the approach allows identifying the places of extreme stresses, which in turn allows choosing the places correctly for deformation marks installation. These conclusions have been proven in a case study of geospatial monitoring of a large sports structure. Based on the simulation of the reconstruction process of the football stadium, the limit horizontal and vertical displacements were found. The accuracy of geodetic networks for geospatial monitoring was assigned using these limit values. At the final step, the results of geospatial monitoring were analyzed using obtained limit values for vertical displacements. Future studies will have to continue to explore the models of structural mechanics in geodesy and identify the circumstances under which they may be applied.

\section{References}

Acosta, L. E., De Lacy, M. C., Ramos, M. I., Cano, J. P., Herrera, A. M., Avilés, M., \& Gil, A. J. (2018). Displacements study of an earth fill dam based on high precision geodetic monitoring and numerical modeling. Sensors, 18(5), $1369-1384$. https://doi.org/10.3390/s18051369

Alizadeh-Khameneh, A. M., Eshagh, M., \& Jensen, A. B. O. (2018). Optimization of deformation monitoring networks using finite element strain analysis. Journal of Applied Geodesy, 12(2), 187-197. https://doi.org/10.1515/jag-2017-0040

Cîrdei, A.-N., \& Onose, D. (2019). Bridge dynamic displacement monitoring using geodetic measurement. Bulletin UASVM Horticulture, 76(1), 25-30. https://doi.org/10.15835/buasvmcn-hort:2018.0027

Connor, J. J., \& Faraji, S. (2016). Fundamentals of structural engineering ( $2^{\text {nd }}$ ed). Springer. https://doi.org/10.1007/978-3-319-24331-3

Eichhorn, A. (2007, September). Tasks and newest trends in geodetic deformation analysis: A tutorial. Paper presented at the $15^{\text {th }}$ European Signal Processing Conference (EUSIPCO 2007), Poznan, Poland.

Gikas, V., \& Sakellariou, M. (2008, May). Horizontal deflection analysis of a large earthen dam by means of geodetic and geotechnical methods. Paper presented at the $13^{\text {th }}$ FIG Symposium on Deformation Measurement and Analysis, $4^{\text {th }}$ IAG Symposium on Geodesy for Geotechnical and Structural Engineering, Lisbon, Portugal.

Hesse, C., Heer, R., Horst, S., \& Neuner, H. (2006, May). A concept for monitoring wind energy turbines with geodetic techniques. Paper presented at the $3^{\text {rd }}$ IAG / $12^{\text {th }}$ FIG Symposium, Baden, Germany.

Jäger, R., \& González, F. (2005, March). GNSS/LPS based online control and alarm system (GOCA) - mathematical models and technical realization of a system for natural and geotechnical deformation monitoring and hazard prevention. Paper presented at the IAG Symposium, Jaén, Spain.

Kapović, Z., Novaković, G., \& Paar, R. (2005). Deformation monitoring of the bridges by conventional and GPS methods. Paper presented at the $5^{\text {th }}$ International Multidisciplinary Scientific GeoConference - SGEM2005, Albena, Bulgaria.

Li, H.-N., Yi, T.-H., Yi, X.-D., \& Wang, G.-X. (2007). Measurement and analysis of wind-induced response of tall building based on GPS technology. Advances in Structural Engineering, 10(1), 83-93. https://doi.org/10.1260/136943307780150869

Szostak-Chrzanowski, A., \& Chrzanowski, A. (2004). Physical interpretation of ground subsidence surveys - a case study. Journal of Geospatial Engineering, 6(1), 21-28.

Szostak-Chrzanowski, A., Massiéra, M., Chrzanowski, A., \& Hill, C. J. (2001, March). Use of geodetic monitoring surveys in verifying design parameters of large earthen dams at the stage of filling the reservoir. Paper presented at the $10^{\text {th }}$ FIG International Symposium on Deformation Measurements, Orange, CA, USA.

Welsch, W. M., \& Heunecke, O. (2001, March). Models and terminology for the analysis of geodetic monitoring observations Official Report of the Ad-Hoc Committee of FIG Working Group 6.1. Paper presented at the $10^{\text {th }}$ FIG International Symposium on Deformation Measurements, Orange, CA, USA. 


\section{Notations}

Variables and functions

$e_{\text {force, temperature, manufactoring }}-$ extension due to loads, temperature, and manufacturing.

$\mathbf{F}-$ vector of forces.

$\mathbf{P}$ - vector of loads.

B - matrix of force equilibrium equations.

$\mathbf{e}, \mathbf{e}_{1}-$ vectors of extensions and extensions due to manufacturing errors.

f - matrix of flexibility coefficients for the members.

$\mathbf{U}$ - vector of displacements. 